\title{
Stem Cell Therapies in Peripheral Vascular Diseases - Current Status
}

\author{
Diana Opincariu ${ }^{1,2}$, András Mester ${ }^{1,2}$, Imre Benedek ${ }^{1,2}$, István Benedek ${ }^{1,3}$ \\ ${ }^{1}$ University of Medicine and Pharmacy, Tîrgu Mureș, Romania \\ ${ }^{2}$ Center of Advanced Research in Multimodality Cardiac Imaging, Cardio Med Medical Center, Tîrgu Mureș, Romania \\ ${ }^{3}$ Clinic of Hematology and Bone Marrow Transplantation Unit, Tîrgu Mureș, Romania
}

\section{CORRESPONDENCE}

\section{András Mester}

Str. Gheorghe Marinescu nr. 38

540139 Tîrgu Mureș, Romania

Tel: +40 265215551

E-mail: andras.mester@yahoo.com

\section{ARTICLE HISTORY}

Received: October 2, 2017

Accepted: October 31, 2017
Diana Opincariu • Str. Gheorghe Marinescu nr. 38, 540139 Tîrgu Mureș, Romania. Tel: +40 265215551. E-mail: diana.opincariu@yahoo.ro

Imre Benedek • Str. Gheorghe Marinescu nr. 38 540139 Tîrgu Mures, Romania. Tel: +40 265215551 E-mail: imrebenedek@yahoo.com

István Benedek • Str. Gheorghe Marinescu nr. 38, 540139 Tîrgu Mureș, Romania. Tel: +40 265215551

E-mail: istvan.benedek@umftgm.ro

\begin{abstract}
Peripheral artery diseases include all arterial diseases with the exception of coronary and aortic involvement, more specifically diseases of the extracranial carotids, upper limb arteries, mesenteric and renal vessels, and last but not least, lower limb arteries. Mononuclear stem cells, harvested from various sites (bone marrow, peripheral blood, mesenchymal cells, adipose-derived stem cells) have been studied as a treatment option for alleviating symptoms in peripheral artery disease, as potential stimulators for therapeutic angiogenesis, thus improving vascularization of the ischemic tissue. The aim of this manuscript was to review current medical literature on a novel treatment method - cell therapy, in patients with various peripheral vascular diseases, including carotid, renal, mesenteric artery disease, thromboangiitis obliterans, as well as upper and lower limb artery disease.
\end{abstract}

Keywords: stem cells, peripheral vascular diseases, endothelial precursor cells, therapeutic angiogenesis

\section{INTRODUCTION}

According to the 2017 guideline of the European Society of Cardiology on the management of peripheral artery disease (PAD), the term "PAD" includes all arterial diseases with the exception of coronary and aortic involvement, more specifically diseases of the extracranial carotids, upper limb arteries, mesenteric and renal vessels, and last but not least, lower limb arteries. ${ }^{1}$ Peripheral arterial disorders affect approximately 40 million inhabitants in Europe, leading to increased healthcare costs, as well as high morbidity and mortality rates and impaired health-related quality of life. ${ }^{2-5}$ The most frequently cited cause for PADs with various locations is atherosclerosis, therefore the risk increases with age and exposure to classical cardiovascular risk factors including dyslipidemia, diabetes, chronic tobacco use, arterial hypertension, obesity, and newer factors such as enhanced systemic inflammation, hyperhomocysteinemia and various genotypes. ${ }^{6}$ Ongoing research is required for developing new therapeutic measures for subjects that present no indication for either inter- 
ventional or surgical revascularization - the so called "no-option" patients.

The aim of this manuscript was to review current medical literature on a novel treatment method - cell therapy, in patients with various peripheral vascular diseases, including carotid, renal, mesenteric artery disease, thromboangiitis obliterans, as well as upper and lower limb artery disease.

\section{PERIPHERAL ARTERY DISEASES - MORE THAN WORDS CAN SAY}

As previously mentioned, PADs are located in several vascular sites, leading to devastating repercussions that comprise multiple aspects of the healthcare system from an economical point of view, as well as individual quality of life, morbidities and mortality rates.

Patients with PAD present increased risk for cardiovascular adverse events irrespective of the site of the lesions. Subjects with carotid artery disease have been shown to have increased risk of acute cerebrovascular events, acute myocardial infarction, and cardiac death. ${ }^{7}$ The prevalence of asymptomatic carotid stenoses of $>50 \%$ is $4.2 \%$, showing an increasing rate with age in Europe,${ }^{8}$ while in the United States, the rate of moderate to severe carotid artery disease was found to be $3.9 \% .^{9}$

Upper extremity ischemic disease is less common than lower limb PAD, accounting for less than $5 \%$ of all cases of limb ischemia. ${ }^{10}$ Atherosclerotic disease is rarely the sole culprit of critical ischemia of the upper limbs; more often, Buerger's thromboangiitis obliterans or systemic sclerosis are the responsible causes. ${ }^{11-13}$ Subclavian stenosis is frequently caused by atherosclerotic plaques, with an increasing prevalence from $2 \%$ in the general population, to $9 \%$ in subjects with lower limb PAD. ${ }^{14}$ The clinical presentation of subclavian artery disease includes various symptoms, from hand claudication to several manifestations of the subclavian steal phenomenon, with cerebral hypoperfusion, or, in subjects with coronary bypass grafting and axillo-bifemural bypass, it could lead to chest pain or lower limb claudication respectively. ${ }^{15,16}$

Thromboangiitis obliterans, or Buerger's disease is a non-atherosclerotic segmental inflammatory disease characterized by the presence of thrombosis in the small and medium arterial vasculature, affecting mainly young subjects with a positive history of chronic tobacco use, with frequent distal upper limb involvement, but it can also affect the lower limbs, leading to severe ischemic pain, gangrene of the extremities, and culminating with limb amputation. ${ }^{17}$
Mesenteric artery disease is often undiagnosed in clinical practice, and it causes approximately $5 \%$ of all acute intestinal ischemic events. ${ }^{13}$ The coeliac trunk is more often affected than the superior mesenteric artery, as it was shown by a study on a population undergoing cardiac catheterization, in which the prevalence of mesenteric artery disease was $14 \%$, out of which $11 \%$ was located in the coeliac trunk. ${ }^{18}$

Atherosclerotic renal artery disease has been shown to affect $6.8 \%$ of subjects in the Cardiovascular Health Study, regardless of gender or age, although it affected significantly more male patients than females $(9.1 \%$ versus $5.5 \%$ respectively, $\mathrm{p}=0.05$ ), and its incidence was independently associated with increasing age, LDL cholesterol levels, and increasing systolic blood pressure. ${ }^{19}$ Another study on 866 patients undergoing simultaneous coronary and renal artery angiography, found significant atherosclerotic renal artery stenosis in $39.8 \%$ of cases, from which $22.3 \%$ were with bilateral involvement, while age, female gender, hypertension, left anterior descendant and circumflex artery stenosis of more than $50 \%$ were found to be independent predictors for renal artery stenosis. ${ }^{20}$

Approximately 202 million subjects suffer from lower limb PAD around the globe, showing an increasing incidence with age. The gender distribution varies between lower and middle-income states, where women are more affected than men, and higher income countries, where there is a net male predominance in the non-elderly population. ${ }^{21}$ Critical limb ischemia, the end stage of chronic lower limb PAD, is present in 500-1000 new cases per million, with increasing incidence among diabetic patients, and is not only associated with high morbidity and mortality rates, but also with high risk of limb amputation. ${ }^{22-25}$ The annual amputation rate above and below the knee is between 120 to 500 in every million lower limb PAD subjects. ${ }^{26}$ The death rate related directly to lower limb PAD is 3.5 per 100,000 individuals, but most patients will succumb to complications related to coronary artery disease or stroke, as PAD is a marker for systemic atherosclerotic involvement. ${ }^{13,27}$

\section{THERAPEUTIC USE OF STEM CELLS IN PERIPHERAL ARTERY DISEASES}

Bone marrow-derived stem cells (BMSC) have been studied as a therapeutic option for alleviating symptoms in PAD as potential stimulators for therapeutic angiogenesis, thus improving vascularization of the ischemic tissue and enhancing both perfusion and woundhealing. ${ }^{28}$ Cell therapies with either BMSC or progenitor cells derived from 
peripheral blood may offer ongoing sources of growth factors and structural tissue components for vessel regeneration or neoformation. ${ }^{29}$

Angiogenesis refers to the development of preexisting capillary endothelial tubules as a response to tissue ischemia, being mediated by hypoxia-induced release of vascular growth factors and related citokines..$^{30}$ Arteriogenesis is the development of the collateral vascular network by an increase in the diameter of the preexistent collateral arterioles, which will act as a sustaining vascular network that compensates the function of the occluded vessels. ${ }^{31-33}$ The physiological stimulation of arteriogenesis occurs in conditions of increased shear stress, leading to a mechanical increase in vessel diameter, followed by the activation of adhesion molecules and cytokine release that will attract circulating monocytes, which are actually bone-marrow derived cells. Monocytes activate matrix proteases that will create the spatial conditions needed for vessel growth, and within 3-4 weeks from the occlusion of a large artery, the collateral arteries will be able to provide a proper blood flow to the affected tissue. ${ }^{34,35}$ Several studies have sought to find the role of the bone marrow derived monocytes in the arteriogenesis process, and the findings suggest that the stem cells stimulate artery development not by incorporating into the vessel wall, but by promoting cytokine release, which offer paracrine stimulation of vascular growth. ${ }^{34,36}$

Circulating endothelial progenitor cells (EPC) were first described by Asahara et al. ${ }^{37}$ and were shown to originate from bone marrow-derived monocytes that are present in the vicinity of the collateral vessels. ${ }^{38}$ Another observation that sustains the promoter role of BMSC in arterial collateralization present in PAD, was that the number of circulating monocytic endothelial progenitor cells was lower if risk factors such as diabetes, tobacco use, dyslipidemia, or old age were present. These are the same risk factors associated with failed collateral development and with the severity of PAD. ${ }^{28,39-43}$

These observations have led to the birth of a new concept: therapeutic stimulation of angiogenesis by stem cell infusion. Cell therapy aims to stimulate physiological arteriogenesis, by using an increased number of precursor cells that will provide the required cytokines for an accelerated arteriogenesis. ${ }^{44}$ Several studies on cell therapies for improvement of tissue perfusion have been carried out, with either bone-marrow derived monocytes or peripheral blood mononuclear cells that express surface markers that identify human EPC, more specifically CD133, CD34, KDR (kinase insert domain receptor), and VEGF receptor $2 .{ }^{45-48}$

\section{STEM CELL THERAPIES IN VARIOUS TYPES OF PAD}

\section{Carotid artery disease and stroke}

Although cell therapies in stroke patients do no induce collateral vessel formation, there are several preclinical and clinical studies that have researched the effect of intravenous and intra-arterial stem cell injection for improving the neurological deficits of acute ischemic stroke patients. ${ }^{49-53}$ Preclinical studies have found that the implantation of bone marrow mononuclear cells, which include, among other types, hematopoietic and mesenchymal stem cells, may reduce the size of cerebral infarction and improve the functional outcomes by producing various cytokines and growth factors. ${ }^{54-57}$ These observations have set the base for multiple clinical studies in which stem cells were injected intracerebrally, intravenously, or intra-arterially in patients with acute cerebral ischemia, and all have found potential benefits in cell therapies for stroke patients. ${ }^{58,59}$ However, several questions should be answered by larger randomized controlled clinical trials, regarding the timing (acute or chronic phase of brain ischemia), ${ }^{60,61}$ the type of cell (bone marrow-derived, peripheral blood-derived, fetal cells), ${ }^{49}$ route of delivery (intracerebral, intra-arterial, intravenous), ${ }^{62-65}$ and infusion rates (larger vessels mean increased infusion rates and vice versa), ${ }^{66,67}$ and last but not least, those regarding the safety of the procedure. $58,61,68,69$

\section{Upper limb ischemia}

While there is an increasing number of studies that sustain the clinical benefits of cell therapies in coronary artery disease and lower limb ischemia, ${ }^{70-75}$ there are scarce data on their role in upper limb ischemia, which is rarer, but if present, is associated with significantly worse outcomes and increased mortality rates. ${ }^{76,77}$ There is a whole body of evidence on the beneficial effects of different cell therapies in lower limb PAD, ${ }^{78}$ but there are few data on the effect of angiogenesis stimulation in upper limb ischemia. However, there are reports of several cases with critical ischemia of the upper limb that have benefited from BMSC as an angiogenic inducer. ${ }^{79,80}$ Camerota et al. have reported the case of a 63-year-old diabetic male with bilateral upper limb digital gangrene caused by atherosclerosis. The patient had received several injections at the level of the forearms and hands, in which bone marrow-derived tissue repair cells were delivered with the purpose of improving tissue perfusion. The 1-year follow-up showed a significant improvement in clinical perfusion sings (wound heal- 
ing, no need for analgesics, complete resolution of pain, and improved quality of life), as well as a better perfusion, objectively seen with pletismography. ${ }^{79}$ Nevskaya et al. reported 2 cases with ischemic digital wounds caused by systemic sclerosis, in which the patients had received mononuclear cells derived from the peripheral blood and from the bone marrow. The results showed increased skin perfusion, wound healing, and improved blood flow in the brachial artery in both cases. ${ }^{81} \mathrm{~A}$ study on 7 subjects with hand ischemia (rest pain, non-healing ischemic ulcers), either caused by thromboangiitis or an autoimmune disease, found that at 6 months after the injection of a mixture of CD34+ and CD 133+ cells, all patients presented improved digital-brachial pressure index, lower score on the visual analogue scale for pain, and ulcer healing. ${ }^{80}$ These reports and pilot studies may be suggesting that autologous bone marrow-derived cells could become a safe method for therapeutic angiogenesis in patients with critical hand ischemia as well; however, further research on larger patient populations is required.

\section{Thromboangiitis obliterans}

The role of cell therapies in improving ischemic signs and symptoms of patients with Buerger's disease has been studied in various clinical trials. ${ }^{83-87}$ Subjects with Buerger's disease are not suitable candidates for revascularization procedures in the presence of critical limb ischemia due to the frequent involvement of distal low-caliber arteries. Lee et al. have performed intramuscular implantation of whole bone marrow stem cells in 90 limbs from 67 subjects with symptomatic Buerger's disease and observed significant clinical and angiographical improvement, as well as a decrease in amputation rates. ${ }^{82} \mathrm{Kim}$ et al. carried out a study on 27 patients with lower limb thromboangiitis who were not suitable for surgical or interventional revascularization, in which they implanted isolated EPCs from the bone marrow in the tibial bone, in association with subcutaneous injection of granulocyte colony-stimulating factor (GCS-F). During a mean follow-up of 19.1 months, from 17 limbs with non-healing ulcers, 13 were healed, and 14 patients presented visible collateral growth on the control angiography, while only 6 showed no collaterals. They also found a significant increase in the number of EPCs in the peripheral blood after GCS-F administration. ${ }^{87}$ Motukuru et al. conducted a 6-month follow-up study on nonreconstructible Buerger's disease patients who underwent BMSC transplantation into the calf muscles of the affected limb. After 6 months, patients presented significant improvement in ulcer healing, increased ankle-brachial index $(\mathrm{p}<0.01)$, and transcutaneous oximetry values $(\mathrm{p}<0.01) .88$ Similar results were found by Durdu et al., who injected autologous BMSC after erythrocyte depletion, in various regions with ischemic lesions (gastrocnemius muscle, intermetatarsal region, feet dorsum, or forearm) in $28 \mathrm{pa}$ tients with Buerger's disease, which were followed up for $16.6 \pm 7.8$ months. They observed that $83 \%$ of patients presented ulcer healing, all patients presented relief of rest pain and no need for analgesics, while in $78.5 \%$ of cases, collateral vessels had formed after 6 months from BMSC implantation. ${ }^{89}$ The results of all these studies suggest the positive effects of angiogenesis stimulation with endothelial precursor cells in patients with Buerger's disease, in which established therapies such as smoking cessation or vasodilator therapies have failed, and who, due to the involvement of small-caliber vessels, are not candidates for surgical or interventional revascularization procedures. Thus, there is supporting data regarding the initiation of larger clinical trials for the assessment of cell therapies in subjects with thromboangiitis obliterans.

\section{Mesenteric artery ischemia and reperfusion injury}

Mesenteric ischemia is rarely caused by atherosclerosis ( $5 \%$ of intestinal ischemia cases), ${ }^{13}$ being frequently undiagnosed. Intestinal ischemia is more often caused by necrotizing enterocolitis, trauma, septic shock, strangulated hernias and volvulus, or cardiac surgery, and it presents a very high risk of death. ${ }^{89,90}$ No clinical research on cell therapies in mesenteric atherosclerosis have been conducted, but there are several preclinical studies on the effect of stem cells in intestinal ischemic and reperfusion injuries. ${ }^{91-93}$ Jiang et al. investigated the effect of BMSC in intestinal ischemia on 100 rats in which the superior mesenteric artery was clamped for 45 minutes, followed by the injection of BMSC in the submucosa of the small intestine, followed by reperfusion. ${ }^{93}$ Their results showed a significant reduction and an accelerated recovery of the intestinal barrier dysfunction in the BMSC group. Jensen et al. performed a similar study on a mouse population, in which human adipose-derived stromal cells were infused into the peritoneum, after 60 minutes of clamping the superior mesenteric artery. The results showed a higher 7-day survival, increased mesenteric perfusion, lower inflammatory status, and preserved intestinal architecture for adiposederived stromal cell-treated mice. ${ }^{91}$

Stem cells have been shown to provide benefits in the case of intestinal ischemia and reperfusion injuries in preclinical settings, albeit no data is available on cell therapies in atherosclerotic mesenteric artery stenosis. These early 
observations could represent a stepping stone for future research on the currently developing applications of stem cell therapies.

\section{Renal ischemia}

Atherosclerosis of the renal arteries is one of the major causes of chronic renal disease, which implies the gradual reduction of the glomerular filtration rate (GFR) due to ischemic loss of renal parenchyma, which will eventually lead to $6-27 \%$ of end-stage renal insufficiencies. ${ }^{94,95}$ Restoring the impaired blood flow to the kidney in renal artery stenosis does not always succeed in reestablishing kidney function and improving the GFR; the identification of other restorative therapeutic measures is of utmost importance. ${ }^{96}$ Mesenchymal stem cell therapies for various types of kidney injuries have been the subject of research in many preclinical and clinical studies, most of them focusing on acute kidney injury. ${ }^{97-100}$ The repair mechanism of mesenchymal stem cells (MSC) includes cytokine release and MSC differentiation into renal cells; MSC can be implanted intravenously, intra-arterially, or within the kidney parenchyma. ${ }^{101}$

Ischemic chronic kidney disease caused by renal artery stenosis is characterized by glomerular fibrosis and decreased number of microvessels, with secondary triggering of the renin angiotensin aldosterone cascade, with subsequent vasoconstriction, inflammation and fibrosis. ${ }^{101}$ Preclinical studies on swine models have proven the efficacy of cell therapies in chronic ischemic kidney disease, in which the intrarenal administration of endothelial progenitor cells has led to tissue repair, decreased inflammation and fibrosis. ${ }^{102,103}$ Others have shown that the implantation of MSC in the renal artery, with or without concomitant revascularization, led to an important improvement of kidney function, as well as a decrease in oxidative stress, inflammation, and fibrosis. ${ }^{104,105}$

Saad et al. conducted a clinical study in which 14 subjects with atherosclerotic renovascular disease received an intra-arterial infusion of MSC in association to the standard medical treatment. These subjects were matched by 14 patients who had received medical treatment only. During the 3-month follow-up, the MSC group presented increased cortical perfusion, the renal blood flow rose in the stenotic kidney from $151.8 \mathrm{~mL} / \mathrm{min}$ to $185.5 \mathrm{~mL} / \mathrm{min}$ ( $\mathrm{p}=0.01)$, and kidney hypoxia decreased from $12.1 \%$ to $6.8 \%(\mathrm{p}=0.04)$, as assessed by blood oxygen level-dependent MRI. ${ }^{106}$

The current preclinical and smaller clinical studies on cell therapies in renal artery stenosis and its subsequent damage show that there is hope in restoring renal function in these patients, in which percutaneous revascularization alone is most often not a viable solution for repairing neither the kidney lesions, nor their local and systemic cardiovascular impact; however, further human studies are required for the clinical implementation of the procedure.

\section{Lower limb ischemia}

The rationale for cell therapies in lower limb artery disease is to promote collateralization and angiogenesis, and therefore to improve tissue perfusion and wound healing, and prevent amputations. ${ }^{107}$ Cell therapies in lower limb ischemia are generally reserved for patients who do not present indication for interventional or surgical revascularization, or in whom these methods have failed, more specifically, for no-option critical limb ischemic patients. ${ }^{108,109}$ There is extensive clinical research on the topic of therapeutic angiogenesis in lower limb PAD, showing a clear benefit in various types of precursor cells, either autologous (endothelial precursor cells, BMSC, peripheral blood stem cells, mesenchymal or adipose-derived stem cells) or allogeneic, the latter presenting the disadvantage of possible immune rejection. ${ }^{110}$

Several clinical trials have been conducted on bonemarrow derived mononuclear cells implantation in ischemic lower limbs. The TACT trial (Therapeutic Angiogenesis by Cell Transplantation), one of the first clinical studies on the matter, included a pilot study in which 22 patients with lower limb PAD had received BMSC in one leg and saline solution in the other, and a randomized clinical trial in which other 22 patients with ischemic lower limbs received BMSC in one leg and peripheral blood-derived precursor cells in the other. The results showed that in both studies there were significant improvements in transcutaneous oxygen pressure, pain-free walking time, and ankle brachial index, but the results were better in the patients treated with bone marrow-derived stem cells. ${ }^{111}$ Other trials have also confirmed the efficacy of cell therapies in promoting vessel collateralization, symptom improvement, and wound healing in lower limb critical ischemia. ${ }^{12-116}$ A meta-analysis published by Rigato et al. included 67 studies (randomized and non-randomized clinical trials, and non-controlled studies), on a total number of 2,352 patients with intractable lower limb PAD or critical limb ischemia, and the primary outcome of the studies was limb amputation. ${ }^{12}$ From the analysis of randomized clinical trials, their results showed a $37 \%$ reduction on amputation rates after cell therapies, as well as a $59 \%$ improvement of wound healing, significantly lower rest pain and higher 
ankle-brachial index and tissue oxygen pressure. They also found that intramuscular implantation of cells is more effective compared to the intra-arterial approach, and that bone marrow-derived mononuclear cells are better than peripheral blood cells or mesenchymal stem cells in obtaining successful results. Also, they found no important adverse reactions to cell therapies. ${ }^{112}$

Therapeutic angiogenesis in no-option critical lower limb ischemia is a promising novel treatment method that offers hope of escaping amputation, an improvement in the overall quality of life, pain-free time, and higher values for indicators of tissue perfusion (ankle-brachial index, tissue oxygen perfusion). The extensive preclinical and clinical data on autologous stem cell implantation, either in the muscle or in the artery, or a combination of the two, has the possibility to change the outcome of intractable critical limb ischemia.

\section{THE FUTURE OF STEM CELL THERAPIES IN PAD}

Well-planned randomized controlled studies are still needed to assess the long-term effects of stem cell implantation for different peripheral artery diseases. The use of programmed allogeneic progenitor cells in patients who present autologous stem cell exhaustion could present a new branch in the therapeutic angiogenesis tree, and the recruitment of stem cells from healthy, HLA-matched donors may provide alternative cellular sources that are less affected by chronic associated diseases. ${ }^{117-119}$ Moreover, genetic therapies based on in vivo gene transferring for inducing angio- and arteriogenesis in combination with stem cell transplantation could better the outcome of patients in which all the applied therapeutic measure have failed. ${ }^{107,120}$

\section{CONCLUSIONS}

There are still multiple untouched territories in stem cell research, including their use in therapeutic angiogenesis for various peripheral vascular diseases. However, their efficacy in enhancing tissue oxygenation, angio- and arteriogenesis in the ischemic segment, as well as accelerating wound healing and improving the functional features of the affected organ, has been proved by various researchers in all peripheral artery diseases (carotid, renal, mesenteric, upper and lower limb). Despite the increasing body of data from preclinical studies for renal or mesenteric artery disease, as well as more frequent clinical trials for lower limb ischemia, there is a long road ahead until stem cell implantation will be listed in the thera- peutic guideline recommendations for such disorders, requiring further multicenter randomized clinical trials on larger populations.

\section{CONFLICT OF INTEREST}

Nothing to declare.

\section{REFERENCES}

1. Aboyans V, Ricco JB, Bartelink MEL, et al. 2017 ESC Guidelines on the Diagnosis and Treatment of Peripheral Arterial Diseases, in collaboration with the European Society for Vascular Surgery (ESVS): Document covering atherosclerotic disease of extracranial carotid and vertebral, mesenteric, renal, upper and lower extremity arteries Endorsed by: the European Stroke Organization (ESO)The Task Force for the Diagnosis and Treatment of Peripheral Arterial Diseases of the European Society of Cardiology (ESC) and of the European Society for Vascular Surgery (ESVS). Eur Heart J. 2017;00:1-60.

2. Tendera M, Aboyans V, Bartelink ML, et al. ESC Guidelines on the diagnosis and treatment of peripheral artery diseases: Document covering atherosclerotic disease of extracranial carotid and vertebral, mesenteric, renal, upper and lower extremity arteries: the Task Force on the Diagnosis and Treatment of Peripheral Artery Diseases of the European Society of Cardiology (ESC). Eur Heart J. 2011;32:2851-2906.

3. Fowkes FG, Rudan D, Rudan I, et al. Comparison of global estimates of prevalence and risk factors for peripheral artery disease in 2000 and 2010: a systematic review and analysis. Lancet. 2013;382:1329-1340.

4. Lindgren H, Gottsäter A, Qvarfordt P, Bergman S. All Cause Chronic Widespread Pain is Common in Patients with Symptomatic Peripheral Arterial Disease and is Associated with Reduced Health Related Quality of Life. Eur J Vasc Endovasc Surg. 2016;52:205-210.

5. Regensteiner JG, Hiatt WR, Coll JR. et al. The impact of peripheral arterial disease on health-related quality of life in the Peripheral Arterial Disease Awareness, Risk, and Treatment: New Resources for Survival (PARTNERS) Program. Vasc Med. 2008;13:15-24

6. Piepoli MF, Hoes WA, Agewall S, et al. 2016 European Guidelines on cardiovascular disease prevention in clinical practice. Eur Heart J. 2016;37:2315-2381.

7. Belcaro G, Nicolaides AN, Ramaswami G, et al. Carotid and femoral ultrasound morphology screening and cardiovascular events in low risk subjects: a 10-year follow-up study (the CAFES-CAVE study). Atherosclerosis. 2001;156:379-387.

8. de Weerd M, Greving JP, de Jong AW, Buskens E, Bots ML. Prevalence of asymptomatic carotid artery stenosis according to age and sex: systematic review and metaregression analysis. Stroke. 2009;40:1105-1113.

9. Razzouk L, Rockman CB, Patel MR, et al. Co-existence of vascular disease in different arterial beds: peripheral artery disease and carotid artery stenosis—data from Life Line ScreeningVR. Atherosclerosis. 2015;241:687691.

10. McCarthy WJ, Flinn WR, Yao JS, Williams LR, Bergan JJ. Result of bypass grafting for upper limb ischemia. J Vasc Surg. 1986;3:741-746.

11. Olin JW. Thromboangiitis obliterans (Buerger's disease). N Engl J Med. 2000;343:864-869

12. Papa M, Bass A, Adar R, et al. Autoimmune mechanisms in thromboangiitis obliterans (Buerger's disease): the role of tobacco antigen and the major histocompatibility complex. Surgery. 1992;111:527-531.

13. Widminsky P, Kohl P, Agewall S, et al. 2017 ESC Guidelines on the Diagnosis and Treatment of Peripheral Arterial Diseases, in collaboration with the European Society for Vascular Surgery (ESVS) - Web Addenda. Eur Heart J. 2017;00:1-22.

14. Shadman R, Criqui MH, Bundens WP, et al. Subclavian artery stenosis: prevalence, risk factors, and association with cardiovascular diseases. $J$ Am Coll Cardiol. 2004;44:618-623.

15. Potter BJ, Pinto DS. Subclavian steal syndrome. Circulation. 2014;129:23202323.

16. Saha T, Naqvi SY, Ayah OA, et al. Subclavian Artery Disease: Diagnosis and Therapy. Am J Med. 2017;130:409-416.

17. Liew NC, Lee L, Nor Hanipah Z, et al. Pathogenesis and Management of Buerger's Disease. Int J Low Extrem Wounds. 2015;14:231-235. 
18. Bageacu S, Cerisier A, Isaaz K, Nourissat A, Barral X, Favre JP. Incidental visceral and renal artery stenosis in patients undergoing coronary angiography. Eur J Vasc Endovasc Surg. 2011;41:385-390.

19. Hansen KJ1, Edwards MS, Craven TE, et al. Prevalence of renovascular disease in the elderly: a population-based study. J Vasc Surg. 2002;36:443-451

20. Rokni N, Salarifar M, Hakki Kazazi E, Goodarzynejad H. Frequency and Predictors of Renal Artery Stenosis in Patients Undergoing Simultaneous Coronary and Renal Catheterization. J Teh Univ Heart Ctr. 2012;7:58-64.

21. Fowkes FG, Rudan D, Rudan I, et al. Comparison of global estimates of prevalence and risk factors for peripheral artery disease in 2000 and 2010: a systematic review and analysis. Lancet. 2013;382:1329-1340.

22. Patel MR, Conte MS, Cutlip DE, et al. Evaluation and treatment of patients with lower extremity peripheral artery disease: consensus definitions from Peripheral Academic Research Consortium (PARC). J Am Coll Cardiol. 2015:65:931-941.

23. Dua A, Lee CJ. Epidemiology of Peripheral Arterial Disease and Critical Limb Ischemia. Tech Vasc Interv Radiol. 2016;19:91- 95

24. Varu VN, Hogg ME, Kibbe MR. Critical limb ischemia. J Vasc Surg. 2010;51:230-241.

25. Abu Dabrh AM, Steffen MW, Undavalli C, et al. The natural history of untreated severe or critical limb ischemia. J Vasc Surg. 2015;62:1642-1651.

26. Norgren L, Hiatt WR, Dormandy JA, Nehler MR, Harris KA, Fowkes FG. Intersociety consensus for the management of peripheral arterial disease (TASC II). J Vasc Surg. 2007;45:S5-S67.

27. Criqui $\mathrm{MH}$, Aboyans $\mathrm{V}$. Epidemiology of Peripheral Artery Disease. Circ Res. 2015;116:1509-1526.

28. Lawall $H$, Bramlage $P$, Amann B. Treatment of peripheral arterial disease using stem and progenitor cell therapy. J Vasc Surg. 2011;53:445-453.

29. Botham CM, Bennett WL, Cooke JP. Clinical trials of adult stem cell therapy for peripheral artery disease. Methodist Debakey Cardiovasc J. 2013;9:201-205

30. Hirota K, Semenza GL. Regulation of angiogenesis by hypoxiainducible factor 1. Crit Rev Oncol Hematol. 2006;59:15-26.

31. Voskuil M, van Royen N, Hoefer I, Buschmann I, Schaper W, Piek JJ. Angiogenesis and arteriogenesis; the long road from concept to clinical application. Ned Tijdschr Geneeskd. 2001;145:670-675.

32. Buschmann I, Schaper W. The pathophysiology of the collateral circulation (arteriogenesis). J Pathol. 2000;190:338-342.

33. Heilmann C, Beyersdorf F, Lutter G. Collateral growth: cells arrive at the construction site. Cardiovasc Surg. 2002;10:570-578.

34. Heil M, Ziegelhoeffer T, Mees B, Schaper W. A different outlook on the role of bone marrow stem cells in vascular growth: bone marrow delivers software not hardware. Circ Res. 2004;94:573-574.

35. Kinnaird T, Stabile E, Burnett MS, Epstein SE. Bone-marrow-derived cells for enhancing collateral development: mechanisms, animal data, and initial clinical experiences. Circ Res. 2004;95:354-363.

36. Jin DK, Shido K, Kopp HG, et al. Cytokine-mediated deployment of SDF-1 induces revascularization through recruitment of CXCR4_ hemangiocytes. Nat Med. 2006;12:557-567.

37. Asahara T, Murohara T, Sullivan A, et al. Isolation of putative progenitor endothelial cells for angiogenesis. Science. 1997;275:964-967.

38. Rehman J, Li J, Orschell CM, March KL. Peripheral blood "endothelial progenitor cells" are derived from monocyte/macrophages and secrete angiogenic growth factors. Circulation. 2003;107:1164-1169

39. Imanishi T, Hano T, Sawamura T, Nishio I. Oxidized low-density lipoprotein induces endothelial progenitor cell senescence, leading to cellular dysfunction. Clin Exp Pharmacol Physiol. 2004;31:407-413.

40. Kondo T, Hayashi M, Takeshita K, et al. Smoking cessation rapidly increases circulating progenitor cells in peripheral blood in chronic smokers. Arterioscler Thromb Vasc Biol. 2004;24:1442-1447.

41. Loomans CJ, de Koning EJ, Staal FJ, et al. Endothelial progenitor cel dysfunction: a novel concept in the pathogenesis of vascular complications of type 1 diabetes. Diabetes. 2004;53:195-199.

42. Vasa M, Fichtlscherer S, Aicher A, et al. Number and migratory activity of circulating endothelial progenitor cells inversely correlate with risk factors for coronary artery disease. Circ Res. 2001:89:E1-E7.

43. Zhu S, Liu X, Li Y, Goldschmidt-Clermont PJ, Dong C. Aging in the atherosclerosis milieu may accelerate the consumption of bone marrow endothelial progenitor cells. Arterioscler Thromb Vasc Biol. 2007;27:113-119.

44. Lawall H, Bramlage P, Amann B. Stem cell and progenitor cell therapy in peripheral artery disease. Thromb Haemost. 2010;103:696-709.

45. Sen S, McDonald SP, Coates PT, Bonder CS. Endothelial progenitor cells: novel biomarker and promising cell therapy for cardiovascular disease. Clin Sci (Lond). 2011;120:263-283.
46. Barber $\mathrm{CL}$, Iruela-Arispe ML. The ever-elusive endothelial progenitor cell: identities, functions and clinical implications. Pediatr Res. 2006;59:26-32.

47. Cañizo MC, Lozano F, González-Porras JR, et al. Peripheral endothelia progenitor cells (CD133 _) for therapeutic vasculogenesis in a patient with critical limb ischemia. One year follow-up. Cytotherapy. 2007;9:99102

48. Kudo FA, Nishibe T, Nishibe M, Yasuda K. Autologous transplantation of peripheral blood endothelial progenitor cells (CD34_) for therapeutic angiogenesis in patients with critical limb ischemia. Int Angiol. 2003:22:344-348.

49. Misra V, Lal A, Khouri RE, Chen PR, Savitz SI. Intra-Arterial Delivery of Cell Therapies for Stroke. Stem Cells Dev. 2012;21:1007-1015.

50. Savitz SI, Misra V, Kasam M, et al. Intravenous autologous bone marrow mononuclear cells for ischemic stroke. Ann Neurol. 2011;70:59-69.

51. Battistella V, de Freitas GR, da Fonseca LM, et al. Safety of autologous bone marrow mononuclear cell transplantation in patients with nonacute ischemic stroke. Regen Med. 2011;6:45-52

52. Kamiya $\mathrm{N}$, Ueda M, Igarashi $\mathrm{H}$, et al. Intra-arterial transplantation of bone marrow mononuclear cells immediately after reperfusion decreases brain injury after focal ischemia in rats. Life Sci. 2008;83:433-437.

53. Li Y, Chopp M, Chen J, et al. Intrastriatal transplantation of bone marrow nonhematopoietic cells improves functional recovery after stroke in adult mice. J Cereb Blood Flow Metab. 2000;20:1311-1319.

54. Moniche F, Gonzalez A, Gonzalez-marcos J-R, et al. Intra-arterial bone marrow mononuclear cells in ischemic stroke: a pilot clinical trial. Stroke. 2012;43:2242-2244.

55. Wang QR, Wang BH, Huang YH, Dai G, Li WM, Yan Q. Purification and growth of endothelial progenitor cells from murine bone marrow mononuclear cells. J Cell Biochem. 2008;103:21-29.

56. Kim H, Park J, Choi YJ, et al. Bone marrow mononuclear cells have neurovascular tropism and improve diabetic neuropathy. Stem Cells. 2009;27:1686-1696

57. Krause DS, Theise ND, Collector Ml, et al. Multi-organ, multi-lineage engraftment by a single bone marrow-derived stem cell. Cell. 2001;105:369-377.

58. Kumar A, Prasad M, Jali VP, et al. Bone marrow mononuclear cell therapy in ischaemic stroke: a systematic review. Acta Neurol Scand. 2017;135:496506.

59. Jeong H, Yim HW, Cho YS, et al. Efficacy and safety of stem cell therapies for patients with stroke: a systematic review and single arm meta-analysis. Int J Stem Cells. 2014;7:63-69.

60. Bhasin A, Srivastava M, Bhatia R, Mohanty S, Kumaran S, Bose S. Autologous intravenous mononuclear stem cell therapy in chronic ischemic stroke. J Stem Cells Regen Med. 2012;8:181-189.

61. Banerjee S, Bentley $\mathrm{P}$, Hamady $\mathrm{M}$, et al. Intra-arterial immunoselected CD34+ stem cells for acute ischemic stroke. Stem Cells Trans/ Med. 2014;3:1322-1330.

62. Lees JS, Sena ES, Egan KJ, et al. Stem cell-based therapy for experimental stroke: a systematic review and meta-analysis. Int J Stroke. 2012;7:582588.

63. Janowski M, Walczak P, Date I. Intravenous route of cell delivery for treatment of neurological disorders: a meta-analysis of preclinical results. Stem Cells Dev. 2010;19:5-16.

64. Willing $\mathrm{AE}$, Lixian J, Milliken $\mathrm{M}$, et al. Intravenous versus intrastriatal cord blood administration in a rodent model of stroke. J Neurosci Res. 2003:73:296-307.

65. Yang B, Migliati E, Parsha K, et al. Intra-arterial delivery is not superior to intravenous delivery of autologous bone marrow mononuclear cells in acute ischemic stroke. Stroke. 2013;44:3463-3472.

66. Bharadvaj BK, Mabon RF, Giddens DP. Steady flow in a model of the human carotid bifurcation. Part I-flow visualization. J Biomech. 1982;15:349-362.

67. Tanriover N, Kawashima M, Rhoton AL Jr, et al. Microsurgical anatomy of the early branches of the middle cerebral artery: morphometric analysis and classification with angiographic correlation. J Neurosurg. 2003:98:1277-1290.

68. Hess DC, Wechsler LR, Clark WM, et al. Safety and efficacy of multipotent adult progenitor cells in acute ischaemic stroke (MASTERS) a randomised, double-blind, placebo-controlled, phase 2 trial. Lancet Neurol. 2017:16:360-368.

69. Prasad K, Sharma A, Garg A, et al. Intravenous autologous bone marrow mononuclear stem cell therapy for ischemic stroke: a multicentric, randomized trial. Stroke. 2014;45:3618-3624.

70. van Ramshorst J, Bax JJ, Beeres SL, et al. Intramyocardial bone marrow cell injection for chronic myocardial ischemia: a randomized controlled trial. JAMA. 2009;301:1997-2004. 
71. De Vriese AS, Billet J, Van Droogenbroeck J, Ghekiere J, De Letter JA. Autologous transplantation of bone marrow mononuclear cells for limb ischemia in a caucasian population with atherosclerosis obliterans. J Int Med. 2008;263:395-403.

72. Gyöngyösi M, Hemetsberger R, Wolbank S, et al. Delayed recovery of myocardial blood flow after intracoronary stem cell administration. Stem Cell Rev. 2011:7:616-623.

73. Gyöngyösi M, Wojakowski W, Lemarchand P, et al. MetaAnalysis of Cellbased CaRdiac stUdiEs (ACCRUE) in patients with acute myocardial infarction based on individual patient data. Circ Res. 2015;116:1346-1360.

74. Bura A, Planat-Benard V, Bourin P, et al. Phase I trial: the use of autologous cultured adipose-derived stroma/stem cells to treat patients with nonrevascularizable critical limb ischemia. Cytotherapy. 2014;16:245-257.

75. Takagi G, Miyamoto M, Tara S, et al. Therapeutic vascular angiogenesis for intractable macroangiopathy-related digital ulcer in patients with systemic sclerosis: a pilot study. Rheumatology (Oxford). 2014;53:854-859.

76. Georgiadis GS, Argyriou C, Antoniou GA, et al. Upper limb vascular calcification score as a predictor of mortality in diabetic hemodialysis patients. J Vasc Surg. 2015;61:1529-1537.

77. Bae M, Chung SW, Lee CW, Choi J, Song S, Kim S. Upper Limb Ischemia: Clinical Experiences of Acute and Chronic Upper Limb Ischemia in a Single Center. Korean J Thorac Cardiovasc Surg. 2015;48:246-251.

78. Tateishi-Yuyama E, Matsubara H, Murohara T, et al. Therapeutic Angiogenesis using Cell Transplantation (TACT) Study Investigators. Therapeutic angiogenesis for patients with limb ischaemia by autologous transplantation of bone-marrow cells: a pilot study and a randomised controlled trial. Lancet. 2002;360:427-435.

79. Comerota AJ, Link A, Douville J, Burchard ER. Upper extremity ischemia treated with tissue repair cells from adult bone marrow. J Vasc Surg. 2010:52:723-729

80. Koshikawa M, Shimodaira S, Yoshioka T, et al. Therapeutic angiogenesis by bone marrow implantation for critical hand ischemia in patients with peripheral arterial disease: a pilot study. Curr Med Res Opin. 2006;22:793-798.

81. Nevskaya T, Ananieva L, Bykovskaia S, et al. Autologous progenitor cell implantation as a novel therapeutic intervention for ischaemic digits in systemic sclerosis. Rheumatology (Oxford). 2009;48:61-64.

82. Lee KB, Kang ES, Kim AK. Stem Cell Therapy in Patients with Thromboangiitis Obliterans: Assessment of the Long-Term Clinical Outcome and Analysis of the Prognostic Factors. International Journal of Stem Cells. Int J Stem Cells. 2011:4:88-98

83. Kim DI, Kim MJ, Joh JH, et al. Angiogenesis facilitated by autologous whole bone marrow stem cell transplantation for Buerger's disease. Stem Cells. 2006;24:1194-1200

84. Durdu S, Akar AR, Arat M, Sancak T, Eren NT, Ozyurda U. Autologous bone-marrow mononuclear cell implantation for patients with Rutherford grade II-III thromboangiitis obliterans. J Vasc Surg. 2006;44:732-739.

85. Ishida A, Ohya $Y$, Sakuda $H$, et al. Autologous peripheral blood mononuclear cell implantation for patients with peripheral arterial disease mproves limb ischemia. Circ J. 2005:69:1260-1265.

86. Motukuru V, Suresh KR, Vivekanand V, Raj S, Girija KR. Therapeutic angiogenesis in Buerger's disease (thromboangiitis obliterans) patients with critical limb ischemia by autologous transplantation of bone marrow mononuclear cells. J Vasc Surg. 2008;48:53S-60S.

87. Kim DI, Kim MJ, Joh JH, et al. Angiogenesis facilitated by autologous whole bone marrow stem cell transplantation for Buerger's disease. Stem Cells. 2006;24:1194-1200.

88. Motukuru V, Suresh KR, Vivekanand V, et al. Therapeutic angiogenesis in Buerger's disease (thromboangiitis obliterans) patients with critical limb ischemia by autologous transplantation of bone marrow mononuclear cells. J Vasc Surg. 2008;48:53S-60S

89. Roussel A, Castier Y, Nuzzo A, et al. Revascularization of acute mesenteric ischemia after creation of a dedicated multidisciplinary center. J Vasc Surg. 2015;62:1251-1256

90. Markel TA, Crisostomo PR, Lahm T, et al. Stem cells as a potential future treatment of pediatric intestinal disorders.J Pediatr Surg. 2008;43:1953-1963.

91. Jensen AR, Doster DL, Hunsberger EB. Human Adipose Stromal Cells Increase Survival and Mesenteric Perfusion Following Intestinal Ischemia and Reperfusion Injury. Shock. 2016;46:75-82.

92. Inan M, Bakar E, Cerkezkayabekir A, et al. Mesenchymal stem cells increase antioxidant capacity in intestinal ischemia/reperfusion damage. J Pediatr Surg. 2017;52:1196-1206.

93. Jiang $H, Q u L, L i$, et al. Bone marrow mesenchymal stem cells reduce intestinal ischemia/reperfusion injuries in rats. J Surg Res. 2011;168:127-134.

94. van Ampting JM, Penne EL, Beek FJ, et al. Prevalence of atherosclerotic renal artery stenosis in patients starting dialysis. Nephrol Dial Transplant. 2003: 18:1147-1151.

95. Fatica RA, Port FK, Young EW. Incidence trends and mortality in end-stage renal disease attributed to renovascular disease in the United States. Am J Kidney Dis. 2001;37:1184-1190

96. Tan J, Wu W, Xu X, et al. Induction therapy with autologous mesenchymal stem cells in living related kidney transplants: a randomized controlled trial. JAMA. 2012;307:1169-1177.

97. Textor SC, Lerman LO. Renal artery stenosis: medical versus interventional therapy. Curr Cardiol Rep. 2013;15:409.

98. Sadek EM, Afifi NM, Elfattah LI, Mohsen MA. Histological study on effect of mesenchymal stem cell therapy on experimental renal injury induced by ischemia/reperfusion in male albino rat. Int J Stem Cells. 2013;6:55-66.

99. Lee P, Chien Y, Chiou G, Lin C, Chiou C, Tarng D. Induced pluripotent stem cells without c-Myc attenuate acute kidney injury via downregulating the signaling of oxidative stress and inflammation in ischemia-reperfusion rats. Cell Transplant. 2012;21:2569-2585.

100. Humphreys BD, Bonventre JV. Mesenchymal stem cells in acute kidney injury. Medicine. 2008;59:311.

101. Tan J, Wu W, Xu X, et al. Induction therapy with autologous mesenchymal stem cells in living related kidney transplants: a randomized controlled trial. JAMA. 2012;307:1169-1177.

102. Zhu XY, Lerman A, Lerman LO. Concise Review: Mesenchymal Stem Cell Treatment for Ischemic Kidney Disease. Stem Cells. 2013;31:1731-1736.

103. Chade AR, Zhu X, Lavi R, et al. Endothelial progenitor cells restore renal function in chronic experimental renovascular disease. Circulation. 2009;119:547-557.

104. Chade AR, Zhu XY, Krier JD, et al. Endothelial progenitor cells homing and renal repair in experimental renovascular disease. Stem Cells. 2010;28:1039-1047

105. Ebrahimi B, Eirin A, Li Z, et al. Mesenchymal stem cells improve medullary inflammation and fibrosis after revascularization of swine atherosclerotic renal artery stenosis. PLos One. 2013;8:e67474.

106. Eirin A, Zhu XY, Krier JD, et al. Adipose tissue-derived mesenchymal stem cells improve revascularization outcomes to restore renal function in swine atherosclerotic renal artery stenosis. Stem Cells. 2012;30:1030-1041.

107. Saad A, Dietz AB, Herrmann SMS, et al. Autologous Mesenchymal Stem Cells Increase Cortical Perfusion in Renovascular Disease. J Am Soc Nephrol. 2017;28:2777-2785

108. Benedek T, Kovács I, Benedek I. Therapeutic Angiogenesis for Severely Ischemic Limbs - from Bench to Bedside in Acute Vascular Care. Journa of Cardiovascular Emergencies. 2017;3:160-171.

109. Kum S, Tan YK, Schreve MA, et al. Midterm Outcomes From a Pilot Study of Percutaneous Deep Vein Arterialization for the Treatment of No-Option Critical Limb Ischemia. J Endovasc Ther. 2017; 24:619-626.

110. Chen XP, Fu WM, Gu W. Spinal Cord stimulation for patients with inoperable chronic critical leg ischemia. World J Emerg Med. 2011;2:262-266.

111. Compagna R, Amato B, Massa S, et al. Cell Therapy in Patients with Critical Limb Ischemia. Stem Cells Int. 2015;2015:931420.

112. Tateishi-Yuyama E, Matsubara H, Murohara T, et al. Therapeutic angiogenesis for patients with limb ischaemia by autologous transplantation of bone-marrow cells: a pilot study and a randomised controlled trial. Lancet. 2002;360:427-435

113. Rigato M, Monami M, Fadini GP. Autologous Cell Therapy for Peripheral Arterial Disease: Systematic Review and Meta-Analysis of Randomized, Nonrandomized, and Noncontrolled Studies. Circ Res. 2017;120:1326-1340.

114. Procházka V, Gumulec J, Jalůvka $F$, et al. Cell therapy, a new standard in management of chronic critical limb ischemia and foot ulcer. Cell Transplant. 2010:19:1413-1424.

115. Walter DH, Krankenberg $\mathrm{H}$, Balzer JO, et al. Intraarterial administration of bone marrow mononuclear cells in patients with critical limb ischemia: a randomized-start, placebocontrolled pilot trial (PROVASA). Circ Cardiovasc Interv. 2011;4:26-37.

116. Idei N, Soga J, Hata T, et al. Autologous bone-marrow mononuclear cell implantation reduces long-term major amputation risk in patients with critical limb ischemia: a comparison of atherosclerotic peripheral arteria disease and Buerger disease. Circ Cardiovasc Interv. 2011:4:15-25.

117. Das AK, Bin Abdullah BJ, Dhillon SS, Vijanari A, Anoop CH, Gupta PK. Intraarterial allogeneic mesenchymal stem cells for critical limb ischemia are safe and efficacious: report of a phase I study. World J Surg. 2013;37:915-922.

118. Jialal I, Devaraj $S$, Singh $U$, et al. Decreased number and impaired functionality of endothelial progenitor cells in subjects with metabolic syndrome: implications for increased cardiovascular risk. Atherosclerosis. 2010:211:297-302

119. Fadini GP, Sartore S, Albiero M, et al. Number and function of endothelial progenitor cells as a marker of severity for diabetic vasculopathy Arterioscler Thromb Vasc Biol. 2006:26:2140-2146.

120. Vasa M, Fichtlscherer S, Aicher A, et al. Number and migratory activity of circulating endothelial progenitor cells inversely correlate with risk factors for coronary artery disease. Circ Res. 2001;89:1-7. 